\title{
The Cultural Path of Governance Group Anomie Behavior in Chinese Local Authority
}

\author{
Fengni Gao \\ Academy of Marxism \\ Xi'an University of Architecture and Technology \\ Xi'an, Shaanxi, China 710055
}

\begin{abstract}
From the perspective of culture, the informal system can effectively overcome the legitimacy crisis and the crisis of participation in the local government governance during the transitional period, which is the basic analysis object in governance group anomie behavior of the local government. This paper argues that institutional innovation is an effective means to govern the group anomie behavior. The innovation of the system comes from the conflict of valuation that is the friction between the idea and the system. It will make the local government system innovation effect greatly reduced and will increase the innovation cost, if the flaws corresponding moral concepts, ideology and cultural atmosphere and other informal system during the process of institutional innovation. Therefore, this paper analyzes the cultural path of the informal system, promotes the innovation of the local government's cultural system, and emphasizes the study of cultural values such as moral values, ideology and system spirit. To improve local government governance capacity and institutional innovation level and to avoid the cultural exposure caused by the relative deprivation of mass.
\end{abstract}

Keywords-group anomie behavior; institutional innovation; cultural path

\section{INTRODUCTION}

\section{A. Anomie Implication}

Anomie is a "condition in which society provides little moral guidance to individuals". ${ }^{[1]}$ It is the breakdown of social bonds between an individual and the community, e.g., under unruly scenarios resulting in fragmentation of social identity and rejection of self-regulatory values. ${ }^{[2]}$ It was popularized by French sociologist Émile Durkheim in his influential book Suicide (1897). Durkheim never uses the term "normlessness"; rather, he describes anomie as "derangement", and "an insatiable will". ${ }^{[3]}$ Most sociologists associate the term with Durkheim, who used the concept to speak of the ways in which an individual's actions are matched, or integrated, with a system of social norms and practices... anomie is a mismatch, not simply the absence of norms. Thus, a society with too much rigidity and little individual discretion could also produce a kind of anomie ... Thus; fatalistic suicide arises when a person is too rulegoverned... ${ }^{[4]}$

In the period of social transformation, the old system cannot be immediately disappeared, the new system cannot be established in a short time, in the "breaking" and "legislation" process, the old and new systems will inevitably occur friction and collision, or even some kinds of void and disorder state, called "anomie" ${ }^{[5]}$. Merton argues that "deviant behavior" is the problem of the relationship between a cultural structure and social structure, on the one hand, each social culture to encourage people to pursue a normative goal, on the other hand, each society will provides the means for people to achieve their goals by a formal structure of value identification. ${ }^{[6]}$

\section{B. The Concept of Group Behavior}

1) Abroad on the definition of group behavior: Abroad on the study of social group emergencies is at the forefront of the world, from a sociological point of view. Samuel Huntington, a well-known American political scientist, in his book "Political Order in a Changing Society," mentions that "modernity produces stability and modernization is unstable." Any country in its modernization process will encounter a variety of events affecting the stability of the country. Gustav Le Pen in France in the 19th century and Sigler in Italy focused mainly on "group psychology", pointing out that "a large number of individuals are not enough to form a group "and that only" Groups of people, their thoughts and emotions all go to the same direction and format of a collective psychology, their conscious personality disappeared, ${ }^{[7]}$ So as to be called a real sense of "group." Influenced by Le Pen and inspired ,the American sociologist Robert· Parker wrote a book "crowds and the public" in 1904, this book which distinguished between "crowd" and "public", the characteristics of the crowds and the results of the crowds affected by the implication is to eventually become its leaders tools that its members easy to accept the influence of its leaders of the views and to obedience its leader no resistance; And Parker believes that these phenomena do not occur in a more critical and rational public "public masses", which is Parker's first attempt to study the phenomenon of human clustering. ${ }^{[8]}$ Parker first defined the concept of "collective action" in his book

"Introduction to Sociology" in 1921. He believes that collective behavior is "in the common collective impetus and influence of personal behavior, is an emotional 
impulse". David Popenoe says, "Collective behavior is the behavior that reacts to a common influence or stimulus in a relatively spontaneous, unpredictable, unstructured, and unstable situation; the form of collect behavior is riots, fashion and Pop and panic ". ${ }^{[9]}$ Robertson defined collective behavior as "a way in which many people exhibit a considerable amount of spontaneous and non-structural thinking, feeling and action." [10] "Cluster behavior is spontaneous, relatively unorganized, even unpredictable, and its development is not planned, it depends on the mutual stimulation of the participants," says Stanley Milgram and Tuohy. ${ }^{[11]}$ Smelts argued that collective behavior includes the following characteristics: First, the cluster behavior is guided by a common belief, this belief is different from other beliefs in daily life, it involves threats, intrigue and other non-normal forces; the second, Collective behavior is not determined behavior, its degree of institutionalization is very low; Third, the people involved in collective behavior believe that with the power of the collective can rebuild normal social behavior. ${ }^{[12]}$

2) Chinese scholars on the definition of group behavior: Most Chinese scholars agreeable to David Popenoe's definition of collective behavior: "collective behavior is defined as the behavior of a group of people in a relatively spontaneous, unpredictable, unstructured and unstable situation, Affect or stimulate the behavior of the reaction. Such as Zhang Xian, Shen Hui, Le Guo'an, who believe that collective behavior with spontaneous, fanatic, unconventional and transient characteristics, generally compared with the established social norms in terms of collective behavior in terms of. Scholar Shen Hui in the definition of "collective behavior" also is influenced by Coleman, Simmel, Robertson, but the various groups generally recognize the unpredictability of the behavior of spontaneous and unstructured. [13] This paper also incorporates the definition of cluster behavior by David Popenoe.

\section{BACKGROUND AND METHODOLOGY}

\section{A. Cultural Perspectives Study}

From cultural perspectives study of governance group anomie behavior in Chinese local authority, the informal system can effectively overcome the crisis of legitimacy, integration crisis and participation crisis in China's transitional period. Institutional innovation is an effective means to control the anomie behavior of the group. The innovation of the system comes from the conflict of value that is the friction between the idea and the system. In the process of institutional innovation, if the lack corresponding moral concepts, ideology and cultural atmosphere and other informal system will make the local government system innovation effect greatly reduced, also will increase the innovation cost. ${ }^{[14]}$

This paper analyzes the cultural path of the informal system, promotes the innovation of Chinese local government's cultural system, and emphasizes the study of cultural values such as moral values, ideology and system spirit, and then enhances Chinese local government governance ability and innovation institutionalization level, avoid by cultural contact caused by mass relative deprivation. This informal system of culture can also reduce the uncertainties of Chinese local institutionalized organizational and procedural issues, thus building a governance path in an ecological political.

\section{B. Background}

1) The performance of the cultural aspects of the problem in groups' anomie behavior during Local government governance: After 30 years of reform, China has achieved great success in all aspects. However, there are still many practical problems in the governance of local governments. Local governments are in a period of transition from a regulated government to a service-oriented government, so various systems cannot completely solve the emerging problems. This requires us to find approach to solve this problem, and institutional construction and institutional innovation is one of the very effective ways. Local governments as policy enforcers, it is necessary to fully grasp for all kinds information of every event, but also for the solution to the problem has its own unique consideration, in addition to the implementation of the actors also stand on a more macro level to thinking and working. There are many drawbacks, though in reality some local governments will inevitably be biased in the regulation of various social relations. Including the deviations of value orientation、 the weak awareness of risk and service.

2) The relation of Institution, Institutional Innovation and Culture: Mutual construction of culture and institutions has always been the core of political development. Confucius and Mencius, or Plato and Aristotle of ancient Greece, have been involved in the construction and development of the system of cultural thinking, such as political ideology. Subsequently, the Chambers, Machiavelli and Rousseau studied the relationship between political culture and political system, especially the influence of national characteristics of different regions on the political community.

System is the concrete form of social ideology, ideology belongs to the mainstream culture of social spirit, so it can be said that the system itself and culture are closely related. Through the propaganda and implementation of ideology in order to make the system be in key and be forming the deep cultural structure, thereby is regulating human behavior. By fully paying attention to ideology, social thought, spiritual culture and traditional Chinese culture on the dominant role of material interests, to establish a more stable, unified and suitable for Chinese society, the core value system and moral norms. and gradually eliminate the drastic changes in behavior Anomie, moral anomie and belief crisis.

The purpose of institutional innovation is to make the local government to adapt to the needs of the era of 
institutional framework and to ensure that the democratic, scientific and the rule of law to deal with local governance, to provide timely and quality services to the public. ${ }^{[15]}$ Institutional innovation is an effective means of governance groups anomie behavior, system innovation comes from the value of the conflict, which is one of the impetus to institutional innovation, and the friction between ideas and systems. In the process of institutional innovation, if the lack corresponding moral concepts, ideology and cultural atmosphere and other informal system, it will be greatly reduced the effect of local government system innovation, also will increase the innovation cost. Therefore, only the innovative system is not enough, we must create the cultural atmosphere of respect for the system and the highest standards of action, so as to achieve the purpose of improving system execution. In turn, the perfect formal system is mandatory, which to change the people's ideas and thinking patterns, values, beliefs and morals play a certain role in promoting.

\section{The CUlTural PRoblem OF THE LOCAL GOVERNMENT GOVERNANCE GROUPS ANOMIE}

\section{A. The Value Orientation Deviation of Local Government Guiding Behavior}

Influenced by the specific social and political environment, some local governments have produced certain political psychology and value orientation, such as the excessively superstitious effect on the traditional administrative power, the empty theory, and the commanding tone, the political culture lags behind the political reality, thinking and concept has changed the social and political ecology seriously out of line. Throughout the mass incidents that have occurred in recent years, the timely disposition of the grassroots government has prevented the deterioration of the incident. This disposition has been widely recognized by the general public, but there are some bias in which the grassroots of positioning their role; the way to deal with the event is simple, rude; underestimated the consequences of the event exposure; no psychological preparation; and exacerbate the harm to the society as a whole. Eventually this performance leading to the local government's political trust gradually lost. It not only is not conducive to a fundamental solution to the contradictions among the people, but also make people's emotions instantaneous rise, further intensification of contradictions escalation.

\section{B. The Weak in Risk Prevention Awareness of Local Government}

At present, there are subjective and objective reasons for the frequent occurrence of group anomie. Social structure change, politics, economy and culture are related to objective factors. The deviations in the concept of some local governments' governance are the subjective factors that induce the group to behave improperly. According to the investigation by the State Bureau of Letters and Visits, the direct causes of the misbehavior of the group are from the grassroots level is $80 \%$. The justified or practical difficulties are more than $80 \% .80 \%$ of them should be able to be solved at the local government. ${ }^{[16]}$ Local governments and officials at all levels should be the primary line of defense for the disorganization of groups, but the risk awareness of some local governments is low, and the consequences of misconduct are underestimated. They think the group of anomie is only a small group of "trouble-making" vexatious, so deal with brutal suppression, but the development of the event is unsatisfactory. There is not the normal way to protect the interests of the group, so they take excessive means to attract media attention and get everyone's sympathy. When the majority of the people form resonance, the local government disposal becomes very difficult.

\section{Lack Service Awareness of Local Government}

The traditional government's management purpose is mostly based on their own interests. How to do and what are the local government do is arbitrary decisions, focus on local government's certain interest and personal achievements, personal interests, and rarely take into account the needs of the public. The way of local government management is also a very simple that based on administrative orders. In real life, a small number of government departments and officials for the people lack awareness of service; Service capacity is low; they cannot properly handle the personal interests and vested interests in many cases. Some grass-roots cadres are "serve the people" alienation into "for the boss's service." Some local governments and departments in the process of implementing policy have the wrong behavior "only responsible for central right, not responsible for people," then exacerbating the contradictions between the cadres and the masses and civil conflict.

\section{THE LOCAL GOVERNMENT GOVERNANCE GROUPS ANOMIE BEHAVIOR CULTURAL PATH STRATEGY}

Culture used in this paper, not the material aspects and specific behavior patterns, habits, conventions, traditions, but spirit aspects. According to the informal system cultural path is analyzed in this paper from three aspects: the system spirit, the ideology and the moral value.

\section{A. To Create the Spirit of the System Is the Local Government Governance Groups' Anomie the Cultural Basis}

Human behavior is governed by thoughts, ideas, and spiritual factors. However, human behavior is actually a kind of collective and social common behavior. Therefore, the spirit of cultural factors will inevitably reflect initiation and the formation of customs, rules, laws, institutions and other institutional factors. While the system of factors and the formation of factors will make people's spiritual factors through the institutional factors into material results. That is, human behavior or human activity. The spirit of the system as an integral part of the culture is not only the product of spiritual culture, but also the material and cultural tools. As the intermediary of material culture and spiritual culture, the spirit of the system plays an indispensable role in coordinating the relationship between individuals and groups, groups and society, and so on ensuring the cohesion of 
society, and profoundly affects people's material and spiritual life. ${ }^{[17]}$

The spirit of the system is Montesquieu spirit of law, the inherent "basic tendency" of the system. ${ }^{[18]}$ The 18 th century French thinker Montesquieu said: "The human dominated by a variety of things, namely: climate, religion, law, the principles of governance, customs, habits, the result is here to form a general spirit". [19] Ancient Greek philosopher Socrates in discussing the political order that law-abiding spirit than the law itself is much more important. If there is no law-abiding spirit to consistently dominate the behavior of people, hoping to constantly develop and modify the law to solve social malpractice, which is like a fairy tale "cut Hydra" head, a cut off one will give birth to two Come. This also shows the importance of the spirit of the system, if a good system lacks the support of the corresponding institutional spirit, it may be deformed or even collapse. For some systems in some countries to run smoothly, while in other countries tend to be a mere formality, one of the reasons is no the spirit of the corresponding institutional support. Appropriate institutional spirit can to overcome the inertia and interdependence of the system, we must shape the institutional development and adapt to the spirit of the system to achieve fit between the informal system and the formal system, so as to ensure that China's local government decision-making mechanism to optimize a series of system effective operation.

Technical system defects are easy to solve, the spirit of the system is not a flaw on the system design can be changed. As Montesquieu clarified, "to change these customs and habits, it should not be used to change the law. With the law to change the words, it will become too violent. If someone else's customs and habits to change their habits and customs, if a great change are to be made in his own country, he should use the law to reform what is established by the law, and to change habits determined by custom; It is a very bad strategy to change things that should be changed by custom. ${ }^{[20]}$ The improvement of the spirit of the system can only use this natural approach to gradually complete. It is an extremely long process to cultivate the institutional spirit which is compatible with the system. This requires us to explore and practice constantly in the reform process.

\section{B. Cultivating Socialist Moral Values Is the Core of Cultural Path}

Morality refers to the standard of measurement that measures the proper conduct. The different standards of right and wrong are naturally formed in specific productive capacities, production relations and life forms. A society generally has a socially accepted code of ethics. Only involving personal, family and other private relations of morality said private morality; involved in the public part of the social morality, known as social morality. In addition, morality is an informal public institution. Informal means that there is no law or authority to judge whether it is correct or not. The public mechanism refers to the criterion that all situations can be applied. ${ }^{[21]}$ Moral relativists believe that morality and culture are closely related: although human morality in some aspects of commonality, but in different times, different societies, often have some different moral values; different cultures, the importance of The same moral, in different cultural and social background of the external manifestations, customs and habits are often very far from each other. ${ }^{[22]}$ As the 18 th century British political scientist Burke believed, the habitual response of the individual is more reliable than the conscious observance of the rules or moral creed. ${ }^{[23]}$

Fostering socialist moral values, and strengthening the construction of personal morality. First of all, we must attach importance to the positive development of moral cultivation and self-discipline and careful guidance. Secondly, we need to cultivate the core values of socialism on the basis of the unity of "knowledge" and "practice" to achieve the moral quality of the individual. In the cultivation of specific socialist core values, it is necessary not only to attach to the mass media's function of public opinion communication, but also to encourage and supervise people to consciously change their moral standards through propaganda and positive guidance. Other factors are needed in the spread and cultivation of socialist core values, Such as the guiding mechanism of moral normative evaluation, the guide mechanism of moral norm, the benefit oriented mechanism of moral norm, the gradual perfecting of the regulating mechanism of moral standard flexibility. Finally, the cultivation and promotion of values and the inheritance of Chinese outstanding traditional culture organically combined. The core value of socialism embodies China's outstanding traditional culture, the spirit of the times and the national spirit with patriotism as its core. Therefore, it is necessary to combine the cultivation of the socialist core values with the Chinese traditional culture.

\section{Cultivating Citizens' Civic Consciousness Is the Foundation of Cultural Path}

Ideology belongs to the mainstream culture of the social spirit. It is the comprehension and cognition of things. It is a sense of things. It is the sum of ideas, ideas, concepts, thoughts and values. Sociologist Edward Schiles argues that ideology is the totality of the cognitive and moral convictions of the universe in relation to man and society. ${ }^{[24]}$ Human ideology by thinking ability, environment, information (education, publicity), value orientation and other factors. Different ideologies, the same thing understanding, cognition is also different. ${ }^{[25]}$

The deep reason for the lack public participation in the process of local government decision making lies in the lack citizen consciousness. For most people think they are ordinary people for local management has nothing to do with their own, do not realize their own as a "citizen" should have the responsibility. Mr. Li Shenzhi, a noted thinker, said: "China now recognizes itself as a gap between China and the developed countries in many respects, and it seems to me that the biggest gap is the disparity in people's civic awareness." ${ }^{[26]}$ Since B.C. 2000, the political system and ideology practiced in China has always been despotism. The rulers carry out the obscurantist policy of "the people cannot know it," and the people follow the slavery doctrine of "indecent assault ". Only in the violent social changes caused 
by the peasant revolution, it was only a "rebellion reasonable" short-term damage. However, after the victory of the peasant revolution, immediately as it is to establish the rule of despotism. By the twentieth century, this set of questions was somewhat relaxed, because of its roots are too deep and there is no fundamental change. Therefore, China's "national character" has not been rid of Lu Xun attacked Ah $\mathrm{Q}$ phase. China must catch up with the advanced countries now, must carry out the modernization, and must try hard to cultivate the citizen consciousness. ${ }^{[27]}$

Subject consciousness is the identity and perception of the citizens as citizens of their own in the country. ${ }^{[28]}$ foster citizens of the main body of consciousness is to enhance as the main body of government decision making in the public participation in national political life and local government decision making process demonstrated a high degree of political responsibility and a positive spirit. Through the propaganda of ideology, and outside into the participation activities to make the public aware of their status as citizens and subjectivity, can truly as the local government decision making body should bear the rights and obligations, and promote local government decision making process of public participation.

\section{CONCLUSION}

Through the above analysis, it can be concluded that the local government governance groups anomie behavior cultural path strategy is to create the spirit of the system, cultivating socialist moral values and cultivating citizens' civic consciousness. This informal system can effectively promote the innovation of the local government's cultural system, overcome the legitimacy crisis and the crisis of participation in the local government governance during the transitional period.

\section{ACKNOWLEDGEMENT}

This work was supported by China Scholarship Council (No: 201508615014).

\section{REFERENCES}

[1] Gerber, John J. Macionis, Linda M. (2010), Sociology (7th Canadian Ed.). Toronto: Pearson Canada. P97, ISBN 978-0-13-700161-3.

[2] NYtimes blogs

[3] Mestrovic, Stjepan, Emile Durkheim and the Reformation of Sociology.

[4] Susan Leigh Star, Geoffrey C. Bowker, and Laura J. Neumann, "Transparency at Different Levels of Scale: Convergence between Information Artifacts and Social Worlds", Library and Information Science, University of Illinois, Urbana-Champaign, August 1997.

[5] LIU Huan-ming, CHEN Xue-zhen. Promoting the Construction of Harmonious Government by Innovation of Government System, Academic Exchange, 2007, (12): 39-42.

[6] Robert K. Merton. Social research and social policy [M] Shanghai: Life, Reading, New knowledge. Sanlian Bookstore, 2001.

[7] [Act] Gustave Le Pen. Mob: the public psychology research [M]. Feng Keli, translated. Guilin: Guangxi Normal University Press, 2007. (51).

[8] [United States] Robert Parker. The crowd and the public [M] .1904.
[9] [US] David Popouno, Sociology [M]. Beijing: Renmin University of China Press, 2007: P747.

[10] Robertson, Sociology [M]. Beijing: The Commercial Press 1994: P747.

[11] Kurt W. Buck. Social Psychology [M]. Tianjin: Nankai University Press, 1984: P176.

[12] Neil Joseph Smelser, Theory of Collective Behavior [M]. Free Press 1963.

[13] Li Chen. Domestic network cluster behavior research literature review $[\mathrm{J}]$. Huaihai Institute of Technology: Social Science Edition, 2012 (5): 36-39.

[14] Trudeau, political philosophy Civilization is the essence of politica civilization, Journal of Wuhan University of Technology (Socia Sciences) 2004.02

[15] Journal of North China Institute of Water Conservancy and Hydroelectric Power (Social Science Edition), 2008, (1): 33-35 (in Chinese with English abstract)

[16] Lujie Qu , political philosophy Civilization is the essence of politica civilization, Journal of Wuhan University of Technology (Social Sciences) 2004.02.

[17] http://baike.baidu.com/view/1237164.htm

[18] Cao Peilin: "system aspect", people's publishing house 2005, P22.

[19] [Act] Montesquieu: "On the Spirit of Law", Commercial Press 1982 P305.

[20] [Act] Montesquieu: "On the Spirit of Law", Commercial Press 1982 P310.

[21] The Cambridge Dictionary of Philosophy P.586 morality.

[22] https://zh.wikipedia.org/wiki/index.html.

[23] [English] David Miller, Vernon Bogdano, Blackwell Encyclopedia of Political Science [M]. Deng Zhenglai translate. Beijing: China University of Political Science and Law Press, 2002.81.

[24] Shils, E. 1982, The Constitution of Society. P.202-223. Chicago: The University of Chicago Press.

[25] http://baike.baidu.com/view/435.htm.

[26] Li Shenzhi: "but also to promote political reform", "reform" 1998: (1)

[27] Li Shenzhi: "Revising the Constitution and Civic Education", "Strategy and Management" 1999: (3).

[28] Shilu: "government public decision-making and citizen participation" Social Science Literature Publishing House 2009: P62. 